\title{
A renewed and improved CMAJ
}

W ith this issue we launch a new look for CMAJ. After almost Io years since its last redesign, it had became apparent that the Journal was in need of a refit to meet the changing needs of readers. Our aim was to create a design that would optimize readability; along the way, the process of revamping our presentation provided an opportunity to reflect on how to invigorate the Journal and set new goals.

Readers will at once notice a major change to the cover, which no longer doubles as a contents page. The table of contents is now organized into 3 pages inside the Journal that allow readers to locate articles of interest easily. The News, Analysis and Practice sections will continue to appear at the front of the Journal, but the popular Letters department has moved further back, after Reviews. CMAF's other departments and columns remain in their usual positions.

Many subtle changes have been made to make CMAJ a more efficient read for physicians who, typically, don't have much time at their disposal. With Earthlore Communications, an Ottawa design firm, we overhauled typeface, page layout, tables and graphs to help achieve this. We hope you will find the result aesthetically pleasing, but our primary goal was always to increase readability: to help readers navigate through the Journal content and extract useful information with relative ease - for example, with the new editors' synopses that now appear with Research articles.

Richard Horton, editor of The Lancet, has expressed the idea that a medical journal has a soul. Constructing the new look certainly required us to examine the Journal's persona: a new face was needed, one that would be respectful of the Journal's past while anticipating its future. Refurbishing the Journal also seemed to us like renovating a space - a space devoted to reason and discourse; a space with its own unique ambience; a structure that houses a body of work - its raison d'etre - and in so doing helps to make that work accessible and intelligible.

The redesign of any journal invariably helps to energize it and mandates its keepers to reflect on the journal's present and future. CMAJ has made important strides in the past several years. The Journal's Impact Factor, one measure of the importance of a journal, has doubled since 2001 to 5.9; $C M A J$ is ranked $5^{\text {th }}$ in the world among general medical journals. This gain is largely because of $C M A$ 's increasing international readership - which, in turn, is driven by the electronic edition of the Journal at www.cmaj.ca. Our Web site now receives over I. 5 million hits per month, and of the top 5 general medical journals, is the only site that has maintained free access to its entire content online. The benefits of increased readership are plain: more readers translate into more prospective authors; the resultant increased competition among submissions affords the editors the opportunity to publish better articles.

What can readers expect in the future? We will continue to develop and expand the front sections of the Journal to provide highly readable articles that will offer insight into important clinical issues and keep readers up to date on developments in health care and medicine. We will continue to build on $C M A F$ 's established strengths in public health and health policy research. At the same time, we realize that to be relevant to our core readership of practising clinicians, CMAJ must also publish articles that promote the understanding of clinical medicine. As such, an important editorial goal for the future will be to become a major source for the publication of randomized controlled trials and clinically oriented research that is relevant to practising physicians. To help achieve this, we will now automatically fast-track all RCTs submitted to the Journal and aim to publish accepted papers within 4 weeks of submission.

As Canada's leading medical journal, we will naturally continue to publish pieces that are important and relevant to health care in this country, but as national boundaries have become increasingly irrelevant to science and medicine, the most competitive manuscripts are those that make a contribution to the world's literature. In this issue, we publish a study that demonstrates the mortality attributed to a hypervirulent strain of Clostridium difficile that caused an outbreak in Canada and has been isolated in the US and Europe; featured on the cover of this issue is a review of severe sepsis written by one of the world's foremost experts in the field. Their publication in $C M A J$ is consistent with an over-reaching goal to create a publication that our readers will consider not only important but also indispensable. - CMAJ 